\title{
The epidemiology of inequity: Will research make a difference?
}

\author{
Harald Kristian Heggenhougen \\ Centre for International Health, University of Bergen, \& \\ Department of International Health, Boston University School of Public Health
}

\begin{abstract}
This article is adapted from the presentation: "Research for Global Health. Can it stem the Tide of Inequity?", made to
\end{abstract} the 4th Students' Scientific Conference, Centre for International Health, University of Bergen, 13th of May 2004

\section{INTRODUCTION}

Many are familiar with Ernest Hemingway's novel: For Whom the Bell Tolls and some may know the poem Devotions Upon Emergent Occasions written by John Donne in 1623 from which Hemingway derived his title:

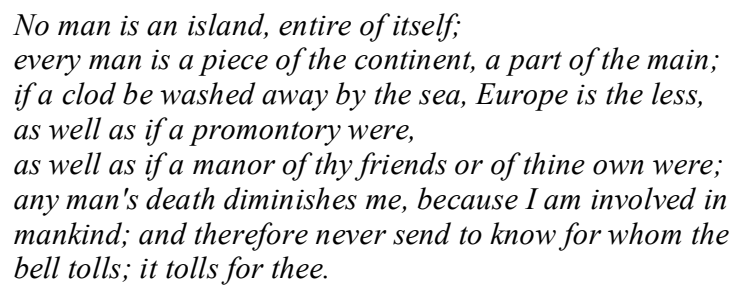

This is a passionate reminder that, as human beings, we are not, or rather, we should not, be isolated individuals, selfishly greedy or alone and lost, but rather our nature, as human beings, ought to lead us to create and be a part of an inter-supportive human community by which we are connected both through care and responsibility.

Epidemiological research, including both biomedical and social determinants of health for different population groups, can guide the development process of creating such inter-supportive communities - healthier communities of equity and without poverty - the creation of which is after all the ultimate goal of all public health research.

One premise of this article is that international (global) epidemiological research is part of an overall development process, with particular attention to improving the health and general welfare of people living in poverty in different parts of the world. Equity, social justice and human rights issues are integral to this process since the degrees to which they are upheld as realities in people's lives are reflected in their epidemiology, in the patterns and prevalence of diseases. Thus, one function of epidemiology is to show this connection. Understanding, and contextualizing research in terms of these and other social (political and economic) determinants of health is paramount for formulating any effective intervention to improve health.

A further premise derives from a concern with the "so what?" question and with the importance of translating research results into policy and action. In sum, health research should be "translational". If this is done then research may reduce the modern public health plague, inequity, and the ill health which follows in its wake $(1,2)$.
This kind of social epidemiological work has gained increasing adherents in recent decades. Yet, many, if not most, epidemiologists, and other public health researchers are against, or at best, ignore such efforts. They are deemed too broad to be meaningful, or, worse, they are opposed for taking attention and energy away from looking at immediate causes and making focused interventions which public health professionals are known to be good at (3). I shall return to these conflicting perceptions of epidemiological and other public health research a little later. At this point I just wish to acknowledge this divide concerning what is an appropriate focus for epidemiological research, and to say I do not agree with Satel and Marmor (3) and those who adhere to their position. Epidemiological efforts can make, and have made, a difference in the arena of social injustice affecting health and general human welfare as well as in reducing immediate disease risks. Further, I think it is not fruitful to present this in "either/or" terms. "Both/and" is a more productive and possible approach.

If we believe, if only partially, in the social determinants of health (4), then we must focus on larger, fundamental factors as well as the more immediate ones (5). If we are serious about improving the health of the public we must of course carry on with the "traditional" public health research and interventions. But we must also focus and attempt to guide social policy formulations and interventions on larger more fundamental issues. I believe such epidemiological research can make a difference.

\section{GLOBALIZATION AND ITS CONSEQUENCES}

With ever increasing globalization, including the Internet, supersonic travel and the internationally pervasive media, much of which can be seen in a positive light, in that, for example, human rights abuses and social injustices more easily come to light, the world is shrinking and we do, in many ways, live in one interactive world.

Unfortunately, this is only partially true. Tremendous benefits have been obtained by vast numbers of people throughout and between countries, for example, life expectancies have increased and infant mortality rates have fallen in many places, and millions now have clean water who did not have it only a few years ago. Yet, the good news is not universal. There is plenty of evidence that the theoretical concept of one inter-supportive world is flawed in practice. More and more voices - one of the 
most recent being that of Nelson Mandela speaking in Tromsø, Norway on June $12^{\text {th }}, 2005$ - are providing us with the "reality check" that the world really is not the mutually supportive home we would like it to be. We live in highly differentiated, local worlds both within and between countries.

While there are yet only a few who fear this may bring ruin upon us all, we all have an inkling of the fact that the benefit, or the misery, of one local world, is intimately linked with the misery or benefit of another, yet we seem to chose not to recognize that as we rob others we unwittingly bankrupt ourselves.

During a talk at the Harvard Medical School in 2001, Bernard Kouchner, the former French Minister of Health and founder of Medecins sans Frontieres, seriously asserted that the current state of intra- and international inequity (unjust inequality) affects the physical, social, economic and mental health of those on both the negative and the privileged sides of the equation (6). This is true, he claimed, not only when we, the privileged, are in close proximity to the destitute in the developed world, or when encountering street children in developing countries. And it affects us through the general knowledge we have nagging at the edges of our consciousness, and our conscience, of the deleterious consequences of inequity on the lives of billions. This profoundly affects our (mental) health. We know that the current state of the world is wrong, he noted. Even though we benefit from that state it constitutes a form of stress because we benefit from it.

It is important to distinguish between inequality and inequity; it is a matter of social justice. The fact that two groups are not equal may not be unjust but rather simply indicating difference, for example that men and women are biologically different. But inequity implies that the difference discussed is unjust, for example, that men and women are not paid the same for the same work, or have unequal power and opportunities in most countries in most societies: "Health inequities exist largely because people have unequal access to society's resources, including education, health care, job security and clean air and water - factors society can do something about" (7).

In his foreword to Paul Farmer's (8) The Pathologies of Power: Health, Human Rights and the New War on the Poor, the Nobel economist Amartya Sen said: "The asymmetry of power can indeed generate a kind of quiet brutality. We know, of course, that power corrupts and absolute power corrupts absolutely. But inequalities of power, in general, prevent the sharing of different opportunities. They can devastate the lives of those who are far removed from the levers of control".

Mounting evidence shows globalization to be increasing the economic and social disparities between the rich and the poor with health opportunities being enhanced for the fortunate and inhibited for those at societies' margins $(7,9)$. In this regard, Frances Baum (10), the Australian Professor of Public Health and author of the book, The New Public Health (11), says that "public health practitioners in rich countries have a responsibility to pose the question of how we can make the impact of economic globalization on health a top public health issue in the $21^{\text {st }}$ Century".

In the next 25 years the world will have another 2 billion people. The great majority of these people will live in developing countries. As Wolfensohn, then head of the World Bank, put it in 2000: "Europe will be the same size in 25 years. But you will have this enormous move in developing countries, with all the attendant stresses if we are not able to deal with the question of poverty" (12). It was in October 2000, a year before the terrible events of the $11^{\text {th }}$ of September, 2001, that Wolfensohn stated, quite prophetically, that, “... it is an issue not just of equity and social justice and morality. It really is an issue of peace, because it is unlikely that you will have stability in a world of inequity. People who have nothing, or have [very] little, or no place to go or no opportunity, react ..."

More and more public health professionals are warning that a globalized world insufficiently tempered by human rights concerns and democratic principles must be amended. Not doing so will mean even more ill health and deprivation especially for the poor. Unfortunately, most of those who could do something about this may not be swayed by ethical arguments; essentially, that, as John Kenneth Galbraith (13) said, "in the good society there cannot, must not, be a deprived and excluded underclass". Many may not even be particularly concerned with the creation of "the good society". But the realization that inaction will not only affect the poor but will also have the much wider consequence of creating a breeding-ground for pandemic violence, as noted by Wolfensohn, has found receptive audiences.

In his book, Infections and Inequalities (1), the infectious disease physician Paul Farmer asks, "If there is no role for any but the profiteers, what sort of 'health care environment' have we created?...By the crude calculus of modern public health, will self-protection become the sole justification for effective measures to contain the plagues of the poor?" (page 279). The answer, unfortunately, seems evident.

He goes on to suggest that the basic question which should occupy us is, how social forces, ranging from political violence to racism, come to be embodied in individual pathology (1). Epidemiological evidence shows us that pathologies concentrate along the fault-lines of societies, among the most deprived and marginalized of the world.

Since the epidemiological evidence concludes that poverty, inequity and health are interlinked, a major focus and function of public health and encompassing epidemiological research must be to stem, and to reverse, the tide of inequity and resultant poor health, $(1,2,4,8,14$ 21).

\section{THE EPIDEMIOLOGY OF POVERTY AND INEQUITY}

Let us look at some figures:

Between 1960 and 1998 the portion of income in the hands of the poorest $20 \%$ of the world's population 
dropped from $2.3 \%$ to $1.2 \%$, while that of the world's richest $20 \%$ rose from $70.2 \%$ to $89 \%$ (9). The richest $20 \%$ consume 160 times that of the poorest $20 \%$ (22).

At least one fifth of the world's population - 1.2 billion people - live in absolute poverty, surviving on US\$1 or less a day, and half the world's population, 3 billion people, live in "moderate poverty", trying to survive on $\$ 2$ or less a day (9). It is not immediately clear how to define "moderate poverty" though it might indicate the possibility of having a house with a roof of metal sheeting rather than one of straw. Paul Farmer makes this distinction in terms of "decent" and "indecent" poverty.

Seventy percent of people living in absolute poverty are women. Indigenous communities suffer poverty at rates far above national poverty rates (23). There are an estimated 100 million street children worldwide (24), and, according to the 2001 Human Development Report 24,000 people starve to death every day (25).

The 2003 Human Development Report (26) reports that 54 nations were poorer in 2003 than they were in 1990. Twenty of these countries are in sub-Saharan Africa, while 17 are in Eastern Europe and the Commonwealth of Independent States. The report documents "an unprecedented backslide ... in some of the world's poorest nations". There are of course pockets of poverty and increasing inequity also in the world's richest countries, not least in the US. The aftermath of Hurricane Katrina and the fate of the astrodome refugees serves as a glaring example.

In Japan, female life expectancy is 85 years, in Sierra Leone it is 36 . In Japan there is ample access to the best of health care while in Sierra Leone many never have access to either a doctor or a nurse. Lee Jong-wook, the WHO Director General, says that such gaps are unacceptable. These health gaps are of course symptoms of wider socioeconomic gaps.

When he accepted the 2002 Nobel Peace Prize, Jimmy Carter said the following: "I was asked to discuss, here in Oslo, the greatest challenge that the world faces. I decided that the most serious and universal problem is the growing chasm between the richest and poorest people on earth" (27).

It must be said again! The tide of inequity is increasing (both between and within nations) and this has significant health consequences for all segments of a society's population. Poverty, certainly, is linked with poor health, but it is particularly the combination of poverty and inequity which is lethal. And, surprisingly to some, the most devastating part of this equation is inequity. Epidemiological research continues to make this quite clear, pointing the way for required changes $(2,4,14,15,20,28,29)$.

\section{INEQUALITIES, INEQUITY AND STRUCTURAL VIOLENCE}

Jim Kim, now at the WHO, and his coauthors showed in some considerable detail in the book Dying for Growth (30) what scores of others have argued as well, namely, that while improved health is loosely tied to overall economic growth there is by no means a guarantee of such a connection.

Depending on the degree of social structural hierarchy, or degree of social cohesion and justice, economic growth in and of itself can mean even greater inequity, and for many, much worse health. The 1985 Rockefeller Foundation publication, Good Health at Low Cost (28), with examples of Costa Rica, Kerala State in India, Sri Lanka and elsewhere, showed much better health indicators in many poorer countries than in richer ones, precisely because of greater equity and more favorable social conditions.

Wilkinson (19), in a study of 23 European countries found that mortality rates, for all social classes, were linked to income within countries rather than to absolute income differences between them. Lower mortality rates were shown in countries with smaller income differences. The study also found that long term rise in life expectancy appeared not to be related to long term economic growth rates.

China, which, in the last decade, has seen tremendous economic growth is an interesting example, showing a widening gap in health statistics for urban as compared to rural populations as well as between other population groups indicating that overall "economic growth alone is not sufficient for improvements in health status" (31).

The socioeconomic divide is, of course, not the only form of inequity leading to poor health; racism and gender issues, to name but two others, have significant health consequences as indicated by a vast literature $(23,32)$. Again, to use China as an example, we learn that China suffers from pervasive gender inequity and that infant mortality for girls has increased since 1987. In 1995 it was more than $25 \%$ higher than for boys. China is also one of very few countries in the world where the suicide rate for women is greater than for men. It is $30 \%$ higher for Chinese women and, unlike in most other countries, the overall rate is higher in rural than in urban areas (31).

Using such evidence, it is difficult to disagree with those who claim that inequity (not only inequity in access to health care services, but over-riding inequity leading to inequality in health) is the major modern plague. A claim which is made while being fully aware of the devastations and ravages of diseases such as HIV/AIDS, TB and Malaria.

The terms "structural violence" and "functional apartheid" $(33,34)$ are sometimes also used when referring to inequitable hierarchical social structures which, similarly, have devastating effect on people's health. The Population Health Forum (35) defines structural violence as excess rates of poor health and death caused by the social and economic structures of society, by decisions about who gets what. They are violent because the harm caused to people are the result of human action (and inaction).

More direct forms of human violence, such as war and civil strife are of course not to be forgotten as lethal instruments of ill health. We should also note that the largest worldwide economic enterprise, by far, is the 
selling of arms, $85 \%$ of which is done by the five permanent members of the UN Security Council.

It was forty years ago that, as a warning against this growing inequity, Adlai Stevenson, the then US Ambassador to the UN, gave the impassioned "Space-Ship Earth" speech to the July, 1965, UN ECOSOC conference (36). It seems an even more apt warning today that allowing a growing divide to go unchecked spells ruin for us all - for those traveling in first class as well as those in steerage: "We travel together, passengers on a little spaceship, dependent upon its vulnerable reserves of air and soil, all committed for our safety to its security and peace, preserved from annihilation only by the care, the work, and I will say the love we give our fragile craft. We cannot maintain it half-fortunate, halfmiserable, and half-free in the liberation of resources undreamed of until this day. No craft, no crew can travel safely with such vast contradictions. On their resolution depends the survival of us all" (36).

\section{RESEARCH CHALLENGES FOR IMPROVING GLOBAL HEALTH AND THE ROLE OF EPIDEMIOLOGY}

There are of course many ways to categorize global health research on equity and health: 1) Equitable research on the diseases that affect most of the world's population; 2) Research on equity of health care and services; 3) Research on more effective and better use of diagnosis, prevention, treatment and care; and 4) Research linking different social, political and economic population characteristics with different health indicators. And running through all four is an urgency to translate research knowledge into action, to use research as a guide for creating "the good society" (13).

The first kind of such global health research on the diseases affecting the majority of humanity has gained momentum in the past several years, especially as a result of the 10/90 problem raised by the Global Forum for Health Research (37). Worldwide, only $10 \%$ of all resources for health research is spent on diseases that account for $90 \%$ of the total global disease burden. We must all be engaged in shifting this priority. The lives of millions could be saved and many millions more could live healthier and happier lives.

Further, we must focus on the second type of global health research to enhance the access to quality medical services for all segments of a country's population, but especially for the poorest and most marginalized. This may also be a matter of new biomedical knowledge for the relatively neglected diseases in the 10/90 debate, but equally important it requires researchers to point out the importance of creating equitable access to existing diagnosis, treatment and medications. This leads directly to the third type of research on more effective use of diagnoses and treatment. The importance of the fourth type of research, especially comparative epidemiology linking socioeconomic inequity with negative health outcomes, is, of course the main argument of this entire article.

These points are not novel (but they continue to be important) and not so different from some of the main points of the WHO, 2004, World Report on Knowledge for Better Health (38): "Global health is characterized by persistent inequities....effective interventions are often not reaching people who need them most... Deep economic inequalities and social injustices continue to deny good health... Positive change does not automatically result from sound evidence alone... The notion of 'knowledge for better health,' therefore, must go beyond the production and passive dissemination of research".

Research is indispensable for reaching the Millennium Development Goals, of which good Health is both a central component and a result. This was the main message of the recent UK House of Commons (39), Science and Technology Committee Report: The Use of Science in UK International Development Policy.

The 2002 Annotated bibliography on equity in health, 1980-2001 by James Macinko and Barbara Starfield (29), in the first issue of the International Journal for Equity in Health, concludes that there are three main types of approaches to health inequities: 1) Increasing or improving ... health services to those in greatest need, 2) restructuring health financing to aid the disadvantaged, and 3) altering broader social and economic structures to influence more fundamental determinants of health inequities. The authors state that there are few articles in the health literature which address the third approach. There is a need to do more.

Several public health specialists, while supporting the first kinds of global health equity research (for example, of challenging the persistence of the 10/90 divide) are strongly against the later, the more fundamental health equity research, indicating that such research is futile and simply done to be "politically correct" (3). Such research, they say, is too broad for epidemiological and other public health researchers to tackle and takes attention and energy away from what public health researchers are really good at and "can do", such as improving water and sanitary conditions and increasing immunization uptake. Satel and Marmor conclude that while it may be seductive to partake in public debate on income distribution it will draw energies and resources away from "the vital issues that the public health profession has addressed so well in the past" (3).

Granted, such work is easier said than done, but, as I stated earlier, it is unhelpful and inaccurate to present this as an "either/or" matter. A "both/and" approach would be more fruitful in the long run. Of course, epidemiologists and other public health researchers should focus on "traditional" topics, and on the "vital issues" which have been addressed in the past, but is also important that we focus on both the immediate and the fundamental risk factors (5) and that we see the interconnections between them.

It must be noted that focusing on the fundamental issues of social inequity and health is not a new effort. Such an encompassing focus has existed since the time of Hippocrates, if not before, and received an impetus in the $19^{\text {th }}$ century. And also within the last 25 years, through the Primary Health Care Declaration, the Ottawa 
Charter, the People's Health Charter, the New Public Health movement, and other recent initiatives such as the UN Commission on the Social Determinants of Health. If, as the mounting epidemiological evidence shows, inequity is a major (I would say, the major) factor contributing to differentiated ill health, and if public health professionals are to be serious then, difficult or not, we can not close our eyes to this obvious connection.

Sudhir Anand (40), at Oxford, stated that there are at least two reasons for investigating inter-group inequalities in health: 1) It will enable us to identify groups at high risk so that public and health policy may be appropriately targeted to improve their health. The UK government's current initiative on inequalities in health is doing precisely this. 2) Inequalities in health which are particularly unjust will be revealed and group inequalities will show that they stem from social rather than natural factors - and may thus be avoidable.

Östlin et al. (32) suggest that "ignoring factors such as socioeconomic class, race [ethnicity] and gender leads to biases in both the content and process of research... If the facts relating to the social distribution of health are not recorded, the problems remain invisible". Looking at these issues is not just a fad, or "politically correctness". Examination of inequitable social realities and related ill health are a necessary and central aspect of global public health (including epidemiological) research. We must use our research to point to ways in which inequity leads to poor health and also to ways in which it can be reduced, ways to advocate for change.

\section{RESEARCHERS AS ADVOCATES FOR CHANGE}

Health research must be used to advocate for social changes, or for what Dr. Julio Frenk, the current Mexican Minister of Health, has called for, namely not only better health policies, but "healthier policies" in all arenas of society. I would suggest that it is within the remit of epidemiological researchers to influence broad social policy formulations as a means by which greater social, economic and political equity can be brought about. Also Dr. Harvey Fineberg, former Dean of the Harvard School of Public Health, and now the President of the U.S. Institute of Medicine, is said to have stated that "A school of public health is like a school of [social] justice" (as quoted in 3 ).

Research for change was the main theme of the October, 2004, issue of the Bulletin of the World Health Organization ("Bridging the Know-Do Gap in global Health"). While contributors dealt with translating research focusing on "immediate" factors, others, such as Sanders et al. (41), focused on the larger social inequity issues: "Most health researchers to date have only studied the world; the point, however, is to change it for the better".
Global health research must focus on ensuring that all have access to the requirements for good health. This is the right of all human beings as the $25^{\text {th }}$ Article of the 1948 Universal Declaration of Human Rights reminds us: "Everyone has the right to a standard of living adequate for the health and well-being of himself and of his family, including food, clothing, housing and medical care and necessary social services, and the right to security in the event of unemployment, sickness, disability, widowhood, old age or other lack of livelihood in circumstances beyond his control".

And as instituted by Dr. Jonathan Mann, the first Director of the WHO AIDS Program and the founder of the Harvard Center for Health and Human Rights, at their graduation, all masters and doctorate graduates from the Harvard School of Public Health are handed the Universal Declaration of Human Rights along with their diplomas. Not only are health and human rights interlinked but public health research must lead to a change for a more universally recognized right to, and realization of, health.

Epidemiology has been, and can continue to be, in the forefront of demonstrating the social basis of ill health and showing not only that change needs to occur but also indicating what should be done, and how this can occur. The pathologist and physician Rudolph Virchow stated in Germany more than 150 years ago that "Medicine is a social science in its very bone and marrow". William Farr in England at approximately the same time, noticed that different classes had very different rates of mortality and he then became committed to social reform and in using social class and health statistics - epidemiological evidence - to advance these reforms. By epidemiological researchers showing evidence on socioeconomic inequity and ill health, there may be a chance of slowly beginning to affect fundamental factors, to stem the tide of growing inequity.

Public health professionals and social epidemiologists should not have to bring about such improved social conditions and consequent improved health alone. These are large development issues which also require a range of different actors, including development agencies and national policy makers. But the involvement of epidemiologists and public health professionals remains crucial and our research should not only be directed at formulating better health policies but 'healthier policies' in all domains. To return to the beginning we are reminded once again by John Donne and Ernest Hemingway that "No man is an island," that no one ought to be isolated and marginalized, and that we should "therefore never send to know for whom the bell tolls, it tolls for thee". We are irresponsible if our research does not (also) engage with this most problematic and prevailing public health issue: the plague of inequity.

\section{REFERENCES}

1. Farmer P. Infections and inequalities: the modern plagues. London: University of California Press, 1999.

2. Wilkinson RG. Unhealthy Societies: the afflictions of inequality. London: Routledge, 1996. 
3. Satel S, Marmor TR. Does inequality make you sick? The dangers of the new public health crusade. The Weekly Standard: July 16, 2001.

4. Marmot M. Social determinants of health inequalities. Lancet 2005; 365 (9464): 1099-1104.

5. Link BG, Phelan J. Social conditions as fundamental causes of disease. J Health Hum Behav 1995 (Spec No): 80-94.

6. Kouchner B. Personal communication, 2001.

7. Evans T, Whitehead M, Diderichsen Bhuiya FA, Wirth M. Challenging Inequities in Health: From Ethics to Action. Oxford: Oxford University Press, 2001.

8. Farmer P. Pathologies of power: health, human rights, and the new war on the poor. Berkeley: University of California Press, 2003.

9. UNDP. Human Development Report. Oxford: Oxford University Press, 1999.

10. Baum F. Health, equity, justice and globalisation: some lessons from the People's Health Assembly. J Epidemiol Community Health 2001; 55 (9): 613-616.

11. Baum F. The New Public Health, 2nd edn. Oxford: Oxford University Press, 2002.

12. Wolfensohn JD. "Poverty and Development. The World Development Report 2000/2001" Keynote address at the Conference on World Poverty and Development: A challenge for the private sector, Amsterdam. 3 Oct, 2000.

13. Galbraith JK. The good society considered: the economic dimension. J Law Soc (Annual Lecture: St. David's Hall, Cardiff Law School, 26 January 1994) 1994: 3-4.

14. Feachem RG. Poverty and inequity: a proper focus for the new century. Bull WHO 2000; 78 (1): 1-2.

15. Kawachi I, Wilkinson RG, Kennedy BP, eds. Income Distribution and Health: A Reader. New York: New Press, 1999.

16. Leon DA, Walt G, eds. Poverty, Inequality and Health: An International Perspective. Oxford: Oxford University Press, 2000.

17. Marmot M, Wilkinson RG, eds. Social Determinants of Health. Oxford: Oxford University Press, 1999.

18. Navarro V, ed. The Political Economy of Social Inequalities: Consequences for Health and the Quality of Life. Amityville, NY: Baywood, 2000.

19. Wilkinson RG. Health inequalities: relative or absolute material standards? BMJ 1997; 314: 591-595.

20. Wilkinson RG. The impact of inequality, how to make sick healthier. London: Routledge, 2005.

21. World Health Organization. The World Health Report. Geneva: WHO, 2004.

22. Rao M, Lowenson R. The political economy of the assault on health. Discussion papers prepared by the Peoples' Health Assembly's Drafting Group. Savar, Bangladesh, Gonoshasthaya Kendra, 2000.

23. Buvenic M, Gwin K, Bates L. Investing in Women: Progress and Prospects for the World Bank. Washington D.C.: Overseas Development Council, 1996.

24. Desjarlais R, Eisenberg L, Good B, Kleinman A. World Mental Health - Problems and Priorities in Low-Income Countries. Oxford: Oxford University Press, 1995.

25. UNDP. Human Development Report. Oxford University Press, 2001.

26. UNDP. Human Development Report. Oxford University Press 2003.

27. Carter J. Nobel Peace Prize Speech, Oslo, 10 December 2002.

28. Halstead S, Walsh J, Warren K. "Good Health at Low Cost." Proceedings of a conference held at the Bellagio Conference Center, Bellagio, Italy, April 29-May 3, 1985.

29. Macinko JA, Starfield B. Annotated bibliography on equity in health, 1980-2001. Int J Equity Health 2002; 1 (1): 139.

30. Kim J, Millen J, Gershman, J, Irwin A, eds. Dying for Growth. Monroe, Me.: Common Courage Press, 2001.

31. Liu Y, Hsiao WC, Eggleston K. Equity in health and health care: the Chinese experience. Soc Sci Med 1999; 49 (10): 1349-1356.

32. Östlin P, Sen G, George A. Paying attention to gender and poverty in health research: content and process issues. Bull WHO 2004; 82 (10): 740-745.

33. Farmer P. An anthropology of structural violence. Curr Anthropol 2004; 45 (3): 305-325.

34. Heggenhougen HK. The epidemiology of functional apartheid and human rights abuses. Soc Sci Med 1995; 40 (3): 281-284.

35. Population Health Forum. Advocacy for action toward a healthier society, "Structural Violence". http://depts.washington.edu/eqhlth/pages/issues.html\#income.

36. Stevenson A. "Space Ship Earth" speech to the ECOSOC meeting in July 1965.

37. Global Forum for Health Research. Health Research for Policy, Action and Practice - Resource Modules, 2004.

38. World Health Organization. World Report on Knowledge for Better Health: Strengthening Health Systems (summary). Geneva: WHO, 2004.

39. United Kingdom, Government of. House of Commons Science and Technology Committee. The Use of Science in UK International Development Policy. Thirteenth Report of Session 2003-04, Volume 1, 2004 : 107.

40. Anand S. The concern for equity in health. Harvard Center for Population and Development Studies Working Paper Series Vol 12, No. 1, 2002.

41. Sanders D, Labonte R, Baum F, Chopra M. Making research matter: a civil society perspective on health research. Bull WHO 2004; 82 (10): 757-763. 